\title{
INDEFERIMENTO DO AUXÍLIO-DOENÇA/ AUXÍLIO-ACIDENTÁRIO DO EMPREGADO CONSIDERADO INAPTO PELO MÉDICO DA EMPRESA*
}

\author{
Joseane da Silva Kroth ${ }^{* *}$ \\ Almiro Eduardo de Almeida**
}

\section{RESUMO}

O presente trabalho trata sobre a situação desumana a que o trabalhador é submetido quando há confronto entre a decisão da perícia médica do INSS e do médico do trabalho. Nesses casos, a autarquia previdenciária argumenta que o trabalhador já possui capacidade laborativa, enquanto o médico da empresa considera o trabalhador inapto para retornar às atividades laborativas. Aborda as consequências desta situação, tendo como principal a insegurança jurídica do trabalhador que, ao recorrer ao judiciário, permanece sem nenhuma fonte de renda até o momento da decisão judicial. 0 trabalho propõe três possíveis soluções para corrigir essa falha em nosso ordenamento jurídico: a competência da justiça do trabalho junto com a responsabilização da empresa quando for o médico do trabalho que proferir laudo médico errôneo; a criação de uma nova hipótese de interrupção contratual; e a interpretação ampliada das hipóteses de interrupção. Além disso, ressalta que perícias médicas com melhor

* Artigo apresentado ao Curso de Bacharelado em Direito do Centro Universitário Metodista - IPA, como requisito parcial para obtenção do Grau de Bacharel em Direito.

** Graduanda do Curso de Bacharelado em Direito do Centro Universitário Metodista - IPA.

*** Orientador do artigo, Doutor em Direito e professor do Curso de Bacharelado em Direito do Centro Universitário Metodista - IPA. 
qualidade previne essa situação, sendo o melhor para todos os envolvidos. Por fim, fala sobre a responsabilidade médica e social do perito.

Palavras-chave: Benefício. Indeferimento. Desumano. Perícia. Recurso.

\section{DISABILITY INSURANCE REJECTION/ACCIDENT EM- PLOYEE ASSIS- \\ TANCE DEEMED UNFIT BY THE COMPANY PHYSICIAN}

\section{ABSTRACT:}

The present work is about the inhuman situation to which the worker is subjected when there is confrontation between the decision of the medical expertise of the INSS and the occupational physician. In these cases, the social security authority argues that the employee already has work capacity, while the company considers the worker unfit to return to labor activities. The paper discusses about the consequences of this situation, a main one being the legal insecurity of the worker that, resorting to using the judiciary system, remains without any source of income until the Court decision. The paper proposes three possible solutions to fix this flaw in our legal system: the jurisdiction of the labor court along with accountability of the company when the occupational physician to deliver erroneous medical reports; the creation of a new chance of interruption of contract; and the expanded interpretation of the chance of interruption. In addition, it points out that better quality in medical expertise prevents this situation, being the best to everyone involved. Lastly, it talks about the expert's medical and social responsability.

Keywords: Benefit. Rejection. Inhuman. Expertise. Appeal.

\section{INTRODUÇÃO}

Baseando-se em uma metodologia de abordagem hipotética-dedutiva será desenvolvido o estudo de uma situação fática corriqueira no ordenamento jurídico brasileiro e apresentada as possíveis soluções do problema. 0 fato que baseia o estudo do presente trabalho é a situação vulnerável em que o trabalhador é submetido quando há conflito na decisão do médico do INSS e o médico do trabalho.

No contexto jurídico brasileiro contemporâneo, observamos que há uma ausência de previsão legal para regularizar um fato social de suma importância no cotidiano dos brasileiros. É o caso 
dos trabalhadores acometidos de diversas enfermidades que lhe causam prejuízo à saúde e os impossibilita de seguir sua rotina de trabalho. Existe, portanto, como suporte para esse trabalhador, benefícios concedidos pelo Instituto Nacional de Seguridade Social - INSS. Todavia, há, em uma quantidade muito significativa, casos em que o beneficiário, após se submeter à perícia médica de manutenção do benefício, seja liberado para voltar ao trabalho mesmo o médico da empresa lhe considerando inapto.

A seguridade social, conforme prevê o Art. $1^{\circ}$ da Lei $n^{\circ}$ 8.212/91, compreende um conjunto de ações do poder público e da sociedade que visam assegurar direitos relativos à saúde, à assistência social e à previdência. 0 principal objetivo é proporcionar aos membros da sociedade a segurança de ter alguns direitos básicos garantidos. Ao decorrer do trabalho apresentaremos os benefícios relacionados à doença e ao acidente do trabalho, assim como suas consequências no contrato de trabalho.

Deste modo, podemos perceber que o INSS, órgão que gerencia todos os benefícios concedidos pela Seguridade Social, tem o dever de conceder ao cidadão o benefício que o mesmo tiver direito. No entanto, como veremos nas próximas seções, este dever nem sempre é cumprido com plenitude. Uma vez que há casos em que o resultado da perícia médica é de indeferimento do benefício, determinando que o trabalhador retorne ao labor, mesmo o médico do trabalho ou do trabalhador atestandoa permanência da incapacidade laborativa.

Essa situação causa grande prejuízo ao trabalhador, visto que ficam impedidos de retornar a sua rotina de trabalho. Até que a situação se resolva, o trabalhador é colocado em uma situação de extrema vulnerabilidade, tendo que viver sem nenhuma fonte de renda, não possuindo nem o mínimo existencial, conforme fica evidenciado na análise jurisprudencial. Há casos, inclusive, que o trabalhador possui alta do INSS, sem nem passar pela perícia médica, é o caso da alta programada. 
Esse problema pode ser evitado mediante de perícias médicas com maior qualidade e resultados precisos. De modo que o trabalhador não precise recorrer judicialmente da decisão para poder ter seu direito ao benefício previdenciário concedido.

Por fim, buscaremos apresentar possíveis soluções ao trabalhador. Iniciaremos o trabalho apresentando os benefícios previdenciários relacionados à doença ou acidente do trabalho.

\section{BENEFÍCIOS PREVIDENCIÁRIOS RELACIONADOS À DOENÇA OU ACIDENTE DO TRABALHO}

A previdência social é um órgão de extrema importância na vida do trabalhador, posto que,é sua função dar um suporte social ao trabalhador quando esse se encontra em situação de vulnerabilidade devido ao acometimento de doença ou acidente de trabalho. A previdência age na forma de um seguro, o trabalhador realiza uma contribuição mensal para que, se necessário, possa usufruir de alguns benefícios, dentre eles: o auxílio-doença, o auxílio-acidentário e o auxílio-acidente.

\subsection{AUXÍLIO-DOENCA}

0 benefício do auxílio-doença tem como fundamento jurídico o Art. 59 da Lei no 8.213/91:

O auxílio-doença será devido ao segurado que, havendo cumprido, quando for o caso, o período de carência exigido nesta Lei, fica incapacitado para seu trabalho ou para a sua atividade habitual por mais de 15 (quinze) dias consecutivos ${ }^{1}$.

O autor João Ernesto Aragonés Viannatraz o conceito de auxílio-doença:

$1 \quad$ BRASIL, Lei no 8.213 de 24 de julho de 1991. 
O auxílio-doença será devido ao segurado que ficar incapacitado para o seu trabalho ou para sua atividade habitual por mais de 15 dias consecutivos. Não é devido o benefício ao segurado que se filiar ao RGPS já portador de doença ou lesão invocada como causa para sua concessão, salvo quando a incapacidade sobrevier por motivo de progressão ou agravamento dessa doença ou lesão².

Segue, neste mesmo sentido, o entendimento da Súmula 25 da Advocacia Geral da União - AGU:

Será concedido auxílio-doença ao segurado considerado temporariamente incapaz para o trabalho ou sua atividade habitual, de forma total ou parcial, atendidos os demais requisitos legais, entendendo-se por incapacidade parcial aquela que permita sua reabilitação para outras atividades laborais ${ }^{3}$.

Quando, por motivo de doença, se fizer necessário que o trabalhador se afaste de suas atividades laborativas, poderá requerer o benefício do auxílio-doença junto ao INSS. Desde que o afastamento seja por um lapso temporal superior a 15 (quinze) dias e que tenha sido cumprido o período de carência. Além disso, a enfermidade não poderá ser pré-existente ao início das contribuições previdenciárias, exceto quando o pedido decorrer de uma progressão ou de um agravamento, conforme extraímos da obra de Miguel Horvath Junior (2010) ${ }^{4}$.

Marina Vaques Duarte ${ }^{5}$ explica que a carência será de 12 (doze) contribuições mensais.Se o trabalhador perder a quali-

2 VIANNA, João Ernesto Aragonés.Curso de Direito Previdenciário. São Paulo: Editora Atlas, 2013, p. 531.

3 BRASIL, Súmula 25 da Advocacia Geral da União - AGU.

4 JUNIOR, Miguel Horvath.Direito Previdenciário. São Paulo: Editora QuartierLatin, 2010, p. 340.

5 DUARTE, Marina Vasques.Direito Previdenciário. São Paulo: Editora Verbo Jurídico, 2012, p. 435. 
dade de segurado,necessário aguardar novamente o período de carência para solicitar o benefício.

A concessão do auxílio-doença está sujeita a comprovação da incapacidade laborativa em exame realizado pela perícia médica da Previdência Social. Conforme o autor Alberto de Vargas explica em sua obra ${ }^{6}$, após o término do período estipulado para o recebimento do benefício, se o trabalhador ainda estiver incapacitado para o labor, necessário se faz realizar um pedido de prorrogação e se sujeitar a nova perícia médica, ela vai determinar se o trabalhador está capacitado, devendo, portanto, retornar ao labor, ou permanecer incapacitado devendo continuar recebendo o benefício previdenciário.

Os autores Carlos Alberto Pereira de Castro e João Batista Lazzari, na obra Manual de Direito Previdenciário7, "entendem que o principal gargalo no processamento de demandas de concessão de restabelecimento dos benefícios por incapacidade está na perícia médica". Ressaltando, portanto, a importância de sua realização, visto que é ela que decide sobre a concessão/ prorrogação do benefício.

0 art. 60 da Lei no 8.213/91 prevê o direito ao segurado de receber o auxílio-doença até o fim de sua incapacidade laborativa, vejamos:

O auxílio-doença será devido ao segurado empregado a contar do $16^{0}$ (décimo sexto) dia do afastamento da atividade, e, no caso dos demais segurados, a contar da data do início da incapacidade e enquanto ele permanecer incapaz ${ }^{8}$.

Caso o trabalhador não possa retornar a sua atividade habitual, de forma definitiva, em decorrência da doença, será submetido ao processo de reabilitação profissional, de acordo com os ensina-

6 VARGAS, Alberto de.Direito a reabilitação profissional. São Paulo: Editora LTr, 2017.

7 CASTRO, Carlos Alberto Pereira de; LAZZARI, João Batista. Manual de Direito Previdenciário. São Paulo: Editora Forense, 2014, p. 787.

$8 \quad$ BRASIL. Art. 60 da Lei 8.213 de 24 de junho de 1991. 
mentos de Alberto de Vargas ${ }^{9}$. Neste processo o trabalhador será reabilitado para desempenhar outra atividade que não prejudique sua saúde. Até que esse processo seja concluído, o trabalhadorpermanecerá recebendo o benefício e cessará o recebimento quando ele estiver devidamente habilitado para desempenhar a nova atividade. A reabilitação é uma alternativa para que o trabalhador retorne ao trabalho sem se prejudicar, pois o ele pode estar incapacitado para uma determinada função, mas capacitado para outras. Um exemplo é alguém que trabalha como carteiro e desenvolve uma lesão na coluna não podendo carregar peso, esse trabalhador está incapacitado para o trabalho como carteiro, mas poderá ser reabilitado para uma função administrativa.

\subsection{AUXÍLIO-ACIDENTÁRIO}

0 auxílio-acidentário é o benefício que o trabalhador faz jus quando sofre algum acidente de trabalho. Ele está previsto no Art. 19 da Lei no 8.212/91, vejamos:

Acidente de trabalho é o que ocorre pelo exercício do trabalho a serviço da empresa ou de empregador doméstico ou pelo exercício do trabalho dos segurados referidos no inciso VII do Art. 11 desta Lei, provocando lesão corporal ou perturbação funcional que cause a morte ou a perda ou redução, permanente ou temporária, da capacidade para o trabalho ${ }^{10}$.

Viannaconceitua o auxílio-acidentário da seguinte forma:

0 artigo 19 da Lei no 8213/91 define o acidente do trabalho como o que decorre pelo exercício do trabalho a serviço da empresa ou pelo exercício do trabalho dos segurados especiais, provocando lesão corporal ou perturbação ${ }^{11}$ funcional que cause a

9 VARGAS, Alberto de.Direito a reabilitação profissional, São Paulo: Editora LTr, 2017.

10 BRASIL. Art. 19 da Lei no 8.213 de 1991.

11 VIANNA, João Ernesto Aragonés.Curso de Direito Previdenciário. São Paulo: Editora Atlas, 2013, p. 623. 
morte ou a perda ou a redução, permanentemente ou temporária, da capacidade para o trabalho ${ }^{12}$.

A Lei Previdenciária considera acidente de trabalho as seguintes entidades mórbidas, conforme art. 20, I,II da Lei 8.213/91:

I) Doença profissional, assim entendida a produzida ou desencadeada pelo exercício do trabalho peculiar a determinada atividade e constante da respectiva relação elaborada pelo Ministério Previdência Social;

II) Doença do trabalho, assim entendida a adquirida ou desencadeada em função de condições especiais em que o trabalho é realizado e com ele se relacione diretamente, constante da relação $\operatorname{acima}^{13}$.

Não são consideradas como doença do trabalho, de acordo com o disposto no Art. 20, §1ํ da Lei 8.213/91:

I) A doença degenerativa;

II) A inerente a grupo etário;

III) A que não produza incapacidade laborativa; e IV) A doença endêmica adquirida por segurado habitante de região em que ela se desenvolva, salvo comprovação de que é resultante de exposição ou contato direto determinado pela natureza do trabalho ${ }^{14}$.

Equipara-se também a acidente de trabalho, para efeitos do Art. 21 da Lei 8.213/91:

I) 0 acidente ligado ao trabalho que, embora não tenha sido a causa única, haja contribuído dire-

12 VIANNA, João Ernesto Aragonés. Curso de Direito Previdenciário. São Paulo: Editora Atlas, 2013, p. 531.

13 BRASIL. Art. 20, I, II da Lei 8.213 de 1991.

14 BRASIL. Art. 20, §1으 da Lei 8.213 de 1991. 
tamente para a morte do segurado, para redução ou perda da sua capacidade para o trabalho, ou produzido lesão que exija atenção médica para a sua recuperação;

II) 0 acidente sofrido pelo segurado no local e no horário do trabalho, em consequência de:

a) Ato de agressão, sabotagem ou terrorismo praticado por terceiro ou companheiro de trabalho;

b) Ofensa física intencional, inclusive de terceiro, por motivo de disputa relacionada ao trabalho;

c) Ato de imprudência, de negligência ou de imperícia de terceiro ou de companheiro de trabalho;

d) Ato de pessoa privada do uso da razão;

e) Desabamento, inundação, incêndio e outros casos fortuitos ou decorrentes de força maior;

III) A doença proveniente de contaminação acidental do empregado no exercício de sua atividade; IV - $O$ acidente sofrido pelo segurado ainda que fora do local e horário de trabalho:

a) $\mathrm{Na}$ execução de ordem ou na realização de serviço sob a autoridade da empresa;

b) Na prestação espontânea de qualquer serviço à empresa para lhes evitar prejuízo ou proporcionar proveito;

c) Em viajem a serviço da empresa, inclusive para estudo quando financiada por esta dentro de seus planos para melhor capacitação da mão de obra, independente do meio de locomoção utilizado, inclusive veículo de propriedade do segurado;

d) No percurso da residência para o local de trabalho ou deste para aquela, qualquer que seja o meio de locomoção, inclusive veículo de propriedade do segurado $^{15}$.

Uma das principais diferenças entre o auxílio-doença e o auxílio-doença acidentário é que neste quem faz a comunicação ao INSS não é o trabalhador, e sim a empresa com o preenchimento da Comunicação do Acidente do Trabalho - CAT. Vejamos:

15 BRASIL. Art. 21 da Lei no 8.213 de 1991. 
Para que o segurado possa fruir dos benefícios e serviços em face de acidente de trabalho ou doença ocupacional, diante dos princípios que regem a concessão de benefício, seria certo que a ele fosse imposta a iniciativa de requerer o benefício. Contudo, em vista das particularidades em que envolvem o evento em questão, estabeleceu o legislador um modo de eximir o segurado ou seus dependentes deste ônus. Assim é que compete à empresa comunicar a ocorrência de acidente de trabalho ou doença profissional ou do trabalho, e, desta maneira, o beneficiário fica desobrigado de tomar a iniciativa de peticionar o benefício a que fala jus ${ }^{16}$.

No caso do auxílio-acidentário, assim como no auxílio-doença é necessário que o trabalhador se submeta a uma perícia médica no INSS para averiguar a enfermidade e determinar o tempo de recebimento do benefício, caso seja necessário solicitar a prorrogação deste, se faz necessário realizar novamente perícia médica, conforme versa Thélio Queiroz Farias em sua obra ${ }^{17}$.

Conforme veremos mais detalhadamente na próximaseção, a segunda grande diferença é que após o término do benefício do auxílio-acidentário o trabalhador terá estabilidade de 12 (doze) meses no emprego, como dispões o artigo 118 da Lei dos benefícios previdenciários:

O segurado que sofreu acidente do trabalho tem garantida, pelo prazo mínimo de doze meses, a manutenção do seu contrato de trabalho na empresa, após a cessação do auxílio-doença acidentário, independentemente de percepção de auxílio-acidente. ${ }^{18}$

O benefício é explicado na Obra Manual de Direito Previdenciário:

16 CASTRO, Carlos Alberto Pereira de; LAZZARI. João Batista. Manual de Direito Previdenciário. Rio de Janeiro: Editora Forense, 2014, p. 637.

17 FARIAS, Thélio Queiroz. Acidente de trabalho.Lemi: Anhanguera, 2011, p. 17.

18 BRASIL. Art. 118 da Lei 8.213 de 1991. 
0 artigo 118 da Lei do RGPS prevê garantia de emprego ao trabalhador que tenha sofrido acidente de trabalho, pelo prazo de doze meses, após a cessação do auxílio-doença decorrente do acidente, independentemente da percepção de auxílio-acidente.

A efetiva fruição da estabilidade, portanto, depende do implemento da condição suspensiva - o retorno ao trabalho, determinado pela perícia médica do INSS, ou seja, a "alta médica". Somente a partir do primeiro dia de retorno ao trabalho é que será computado o prazo de doze meses de estabilidade ${ }^{19}$.

Assim como no auxílio-doença, no auxílio-acidentário há casos em que o trabalhador é liberado para retornar ao trabalho pelo INSS e considerado inapto pelo médico da empresa.

\subsection{AUXÍLIO-ACIDENTE}

O Auxílio-acidente está disposto no artigo 86 da Lei no 8.213/91:

0 auxílio-acidente será concedido, como indenização, ao segurado quando, após consolidação das lesões decorrentes de acidente de qualquer natureza, resultarem sequelas que impliquem redução da capacidade para o trabalho que habitualmente exercia.

§1 0 auxílio-acidente mensal corresponderá a $50 \%$ (cinquenta por cento) do saldo de benefício e será devido, observado o disposto no §5ํㅜ até a véspera do início de qualquer aposentadoria ou até da data do óbito do segurado ${ }^{20}$.

0 auxílio-acidente é o benefício previdenciário devido, como indenização, ao segurado empregado, independente do período de

19 CASTRO, Carlos Alberto Pereira de; LAZZARI, João Batista. Manual de Direito Previdenciário. Rio de Janeiro: Editora Forense, 2014, p. 664-5.

20 BRASIL. Art. 86 da Lei 8.213 de 1991. 
carência, após a consolidação das lesões decorrentes de acidente de qualquer natureza que impliquem na redução da capacidade para o trabalho que habitualmente exercia ou a impossibilidade de desempenho da atividade que exercia na época do acidente. Os autores Carlos Alberto Pereira de Castro e João Batista Lazzariconceituam auxílio-acidente como:

0 auxílio-acidente é um benefício previdenciário pago mensalmente ao segurado acidentado como forma de indenização, sem caráter substitutivo do salário, pois é recebido cumulativamente com o mesmo, quando, após a consolidação de lesões decorrentes de acidente de qualquer natureza - e não somente de acidente de trabalho -, resultem sequelas que impliquem redução da capacidade para o trabalho que habitualmente exercia ${ }^{21}$.

0 valor da indenização a ser recebido pelo trabalhador é de 50\% do benefício que deu origem ao auxílio-doença e receberá até a concessão da aposentadoria e a data do óbito. 0 autor João Ernesto Aragonés Vianna escreve sobre o tema:

O auxílio-acidente mensal corresponderá a 50\% do salário-de-benefício que deu origem ao auxílio-acidente do segurado, corrigido até o mês anterior ao do início do auxílio-acidente, e será devido até a véspera de início de qualquer aposentadoria ou até a data do óbito do segurado. Tendo em vista que é benefício complementar e não substitutivo da remuneração mensal do segurado, pode ter valor inferior ao salário mínimo ${ }^{22}$.

Por conseguinte, a cessação do auxílio-acidente não poderá ocorrer por mera liberalidade do INSS, só cessará nas hipóteses previstas em lei. Os benefícios previdenciários como o auxílio-doença e o auxílio-acidentário geram consequência no contrato de trabalho, como veremos a seguir.

21 CASTRO, Carlos Alberto Pereira; LAZZARI, João Batista. Manual de Direito Previdenciário. Rio de Janeiro: Editora Forense, 2014, p. 797.

22 VIANNA, João Ernesto Aragonés.Curso de Direito Previdenciário. São Paulo: Editora Atlas, 2013, p.565. 


\section{CONSEQUÊNCIA JURÍDICA DOS BENEFÍCIOS PREVI- DENCIÁRIOS NO CONTRATO DE TRABALHO}

0 fato de o trabalhador se afastar do trabalho por motivo de doença ou acidente do trabalho gera uma consequência jurídica no contrato da relação de emprego, podendo causar a suspensão ou interrupção.

\subsection{SUSPENSÕES X INTERRUPÇÃO}

Para melhor aclarar o tema abordado no trabalho, necessário se fazer esclarecer os efeitos jurídicos da percepção dos benefícios previdenciários no contrato de trabalho. Para isso, mister analisar os institutos da suspensão e da interrupção do contrato de trabalho.

Mauricio Godinho Delgadoescreve sobre as distinções existentes entre os dois institutos. Vejamos:

A suspensão consiste em na sustação temporária plena dos efeitos contratuais, preservado, porém, o vínculo entre as partes, ao passo que a interrupção consiste na sustação temporária da principal obrigação do empregado no contrato de trabalho (prestação de serviço e disponibilidade perante o empregador), mantidas em vigor as demais cláusulas contratuais. Enquanto a suspensão corresponde à sustação ampla e recíproca das cláusulas e efeitos contratuais, a interrupção corresponde à sustação restrita e unilateral das cláusulas e efeitos do contrato de trabalho ${ }^{23}$.

A seguir estudaremos ambas as hipóteses.

\subsubsection{Interrupção}

Na interrupção do contrato, o trabalhador não trabalha, mas continua recebendo o salário e contando o tempo de serviço.

23 DELGADO, Mauricio Godinho. Curso de Direito do Trabalho. São Paulo: Editora LTR75, 2011, p. 1010. 
A interrupção contratual do trabalho é a sustação temporária da principal obrigação do empregado no contrato de trabalho (prestação de trabalho e disponibilidade perante o empregador), em virtude de um fato juridicamente relevante, mantidas em vigor todas as demais cláusulas contratuais"24.

Há diversas hipóteses de interrupção do contrato de trabalho:

a) Encargos públicos específicos, em geral de curta duração. Exemplo, o comparecimento judicial como jurado (Art. 430, Código de Processo Penal) ou como testemunha (At. 822 CLT);

b) Os descansos trabalhistas remunerados. Cite-se como exemplo os intervalos intrajornadas e as férias;

c) Licença-maternidade;

d) $\mathrm{O}$ afastamento decorrente de aborto;

e) Interrupção nos serviços da empresa, resultante de causas acidentais ou de força maior;

f) Afastamento em decorrência ao falecimento de um parente próximo;

g) Afastamento em decorrência do casamento;

h) Licença paternidade;

i) Apresentação ao serviço militar;

j) Nos dias em que o empregado estiver comprovadamente realizando vestibular;

k) Afastamento do trabalho por motivo de doença, até os 15 primeiros dias.

Como visto, o principal efeito da interrupção contratual éa sustação das obrigações contratuais mais relevantes do empregado durante o período interruptivo.

É preciso aclarar que em relação ao acidente de trabalho, a partir do $16^{\circ}$ dia de trabalho, há certa controvérsia entre o contrato estar interrompido ou suspenso, Delgado, explica o tema em sua obra:

24 DELGADO, Mauricio Godinho. Curso de Direito do Trabalho. São Paulo: Editora LTR75, 2011, p. 1006-7. 
Conforme se sabe, este período de afastamento não é remunerado pelo empregador (texto expresso no art. 476, CLT, combinando com o art. 20 e seguintes, Lei previdenciária n. 8.213/91) - o que classifica tal lapso temporal como nítida suspensão do contrato. Contudo, a lei, por exceção, preserva, no curso do afastamento, algumas poucas obrigações econômicas empresariais em face de seus empregado (por exemplo, computava-se o período de afastamento para efeitos de indenização e estabilidade celetista, se fosse o caso; igualmente, conta-se tal tempo para fins de depósito de FGTS; do mesmo modo, computa-se o tempo de afastamento inferior a 6 meses no período aquisitivo de férias do empregado). Em virtude dessas vantagens excepcionalmente mantidas em favor do obreiro, é que se instaura alguma controvérsia sobre o enquadramento da presente hipótese de afastamento ${ }^{25}$.

Devido a isso, os casos de acidente de trabalho, posterior ao $16^{0}$ dia de afastamento não estão arrolados na lista de casos de interrupção contratual.

O prazo de retorno do empregado ao labor, em regra geral é imediatamente ao desaparecimento da causa interruptiva.

\subsubsection{Suspensão}

Delgado conceitua a suspensão como:

A suspensão contratual é a sustação temporária dos principais efeitos do contrato de trabalho no tocante às partes, em virtude de um fato juridicamente relevante, sem ruptura, contudo, do vínculo contratual formado. É a sustação ampliada e recíproca de efeitos contratuais, preservado, porém, o vínculo entre as partes ${ }^{26}$.

25 DELGADO, Mauricio Godinho. Curso de Direito do Trabalho. São Paulo: Editora LTR75, 2011, p. 1021.

26 DELGADO, Mauricio Godinho. Curso de Direito do Trabalho. São Paulo: Editora LTR75, 2011, p. 1006. 
De acordo com o autor André Luiz de Almeida ${ }^{27}$, existemtrês modalidades de suspensão do contrato de trabalho: a) suspensão por motivo alheio à vontade do empregado; b) suspensão por motivo ilícito atribuível ao empregado e c) suspensão por motivo ilícito atribuível ao empregado.

a) suspensão por motivo alheio à vontade do empregado;

- Afastamento previdenciário, por motivo de doença, a partir do $16^{\circ}$ dia (auxílio-doença) - art. 476 CLT,

- Afastamento previdenciário, por motivo de acidente de trabalho, a partir do $16^{\circ}$ dia - art. 476, CLT; parágrafo único do art. 4ํ, CLT,

- por incapacidade laborativa - art. 475, caput, CLT; Súmula no 160 , TST;

- Para cumprimento de encargo público obrigatório

- § 1o do art. 483 CLT; Art. 472, caput, CLT),

- Prestação de serviço militar - parágrafo único do art. 4ํㅡ, CLT),

b) suspensão por motivo lícito atribuível ao empregado;

- participação pacífica em greve - art. 7ํㅜ, Lei nํㅗ 7.783/89,

- encargo público não obrigatório - art. 472, combinado com o $§ 1^{\text {o }}$ do art. 483, CLT,

-eleição para cargo de direção sindical - art. 543, $\S 2^{\circ}$, CLT,

- afastamento para qualificação profissional do empregado,

c) suspensão por motivo ilícito atribuível ao empregado;

- suspensão disciplinar - art. 474, CLT,

- instauração de inquérito para apuração de falta grave - art. 494, CLT; Súmula no 197, STF.

27 ALMEIDA, André Luiz Paes de. Direito do Trabalho. São Paulo: Editora Rideel, 2014, p. 455. 
Conforme explica Evaristo de Moraes Filho e Antônio Carlos Flores Moraes em sua obra Introdução ao Direito do Trabalho ${ }^{28}$, a suspensão pode ser típica ou atípica: na suspensão típica o trabalhador não trabalha, não conta tempo de serviço e não recebe salário.Um exemplo é o trabalhador que está afastado da empresa, por motivo de doença ou acidente não relacionados com o trabalho, a partir do $16^{0}$ dia, recebendo o benefício previdenciário. Já na suspensão atípica o trabalhador não trabalha, não recebe salário, mas conta tempo de serviço. É o caso dos trabalhadores que estão afastados de suas funções laborativas, visto terem sofrido acidente de trabalho ou doença relacionada ao trabalho, a partir do $16^{\circ}$ dia.

0 auxílio-doença é devido enquanto o trabalhador está acometido pela enfermidade, estando incapaz para o labor, durante esse lapso temporal, o contrato de trabalho se encontra suspenso, vejamos: "o segurado empregado - urbano ou rural - em gozo de auxílio-doença deve ser considerado pela empresa como licenciado; há, na verdade, a suspensão do contrato de trabalho" (CASTRO; LAZARI, 2014, p.787) ${ }^{29}$.

Um dos efeitos da suspensão e da interrupção do contrato é a impossibilidade de resilição unilateral do contrato por ato do empregador no período que o mesmo se encontra suspenso, como veremos a seguir.

\subsection{DIREITO AO RETORNO E A GARANTIA}

Quando cessado o benefício previdenciário o trabalhador terá o direito a retornar a atividade laborativa e, em alguns casos, possuirá o direito a garantia de emprego.

${ }_{28}$ FILHO, Evaristo de Moraes; MORAES, Antônio Carlos Flores. Introdução ao Direito do Trabalho. São Paulo: Editora LTr, 2010, p. 650.

29 CASTRO, Carlos Alberto Pereira de; LAZZARI, João Batista. Manual de Direito Previdenciário. São Paulo: Editora Forense, 2014, p. 787. 


\subsubsection{Direito ao retorno}

Após desaparecida a causa da suspensão do contrato, o trabalhador deverá se reapresentar a empresa e terá a garantia ao retorno, como explica Maurício Godinho Delgado:

Efeito importante da suspensão contratual é a garantia do retorno obreiro ao cargo anteriormente ocupado, após desaparecida a causa suspensiva (art. 471, CLT). Na mesma linha, a garantia de percepção, no instante do retorno, do patamar salarial e de direitos alcançado em face das alterações normativas havidas (o que significa a absorção das vantagens genéricas oriundas próprias da legislação geral ou normatização da categoria) ${ }^{30}$.

Vejamos o que a doutrina diz em relação ao prazo de retorno:

Após sustada a causa suspensiva do contrato, deve o empregado reapresentar-se ao serviço, retornando a continuidade do contrato de trabalho em todas as suas cláusulas. A injustificada omissão do trabalhador em proceder a essa reapresentação resulta na incidência da figura da justa causa por abandono de emprego (art. 482, "i", CLT) ${ }^{31}$

Conforme os ensinamentos de DELGADO ${ }^{32}$, enquanto o contrato permanecer suspenso em decorrência de uma das hipóteses de suspensão vistas naseção anterior, é vedado que o empregador dispense o trabalhador sem que seja por justa causa. No entanto, a falta grave cometida pelo trabalhador deverá ocorrer dentro do próprio período de suspensão do contrato, como por

30 DELGADO, Mauricio Godinho. Curso de Direito do Trabalho. São Paulo: Editora LTR75, 2011, p. 1014.

31 DELGADO, Mauricio Godinho. Curso de Direito do Trabalho. São Paulo: Editora LTR75, 2011, p. 1016.

32 DELGADO, Mauricio Godinho. Curso de Direito do Trabalho. São Paulo: Editora LTR75, 2011, p. 1014. 
exemplo, o trabalhador ir até a empresa, dentro do período em que o contrato estiver suspenso e, após se desentender com seu chefe, agredi-lo fisicamente.

Caso o motivo da justa causa seja anterior à suspensão do contrato, permanecerá a suspensão contratual. Embora,a empresa possa comunicar de imediato ao trabalhador a justa causa aplicada procedendo, após findar o lapso temporal da suspensão do contrato, à efetiva rescisão do contrato.

Conforme se extrai do artigo A análise da incapacidade laborativa e o deferimento de benefícios previdenciários ${ }^{33}$, em muitos casos ocorre que o trabalhador tem "alta médica" do INSS, sem ainda estar apto a retornar a suas atividades laborativas. Essa situação acontece mesmo quando o trabalhador possui atestado de seu médico particular ou do médico do trabalho. Diante disso, tais trabalhadores precisam recorrer judicialmente da decisão do INSS. Porém, até que a decisão seja proferida, o trabalhador fica impossibilitado de retornar as suas atividades laborativas, visto que o médico do trabalho atestou sua incapacidade. Ocorre que, não há nenhuma previsão legal, tampouco jurisprudência sumuladaque esclareça como trabalhador e empregador devem agir em tal situação. Se for determinado judicialmente que o trabalhador está incapacitado obenefício será pago retroativamente. No entanto, às vezes acontece do trabalhador ser despedido, antes da decisão judicial ser proferida, mas se foi constatada a incapacidade do trabalhador, essa despedidaserá inválida, pois o contrato estava suspenso. Essa insegurança, de como agir nessas situações, causa dúvidas e prejuízos à empresa e danos irreparáveis aos trabalhadores que, devido a essa situação, não têm condições sequer de continuar com seu tratamento médico, como veremos na análise jurisprudencial.

33 PASSOS, Fabio Luiz dos. A análise da incapacidade laborativa e o deferimento de benefícios previdenciários. São Paulo: LTr, 2015, p. 12. 


\subsubsection{Garantia}

A garantia de emprego é o direito que assegura ao trabalhador provisoriamente a segurança de que não será dispensado de maneira arbitrária pelo prazo estipulado em lei.

É válido destacar a diferença entre estabilidade e garantia de emprego, visto que embora haja forte proximidade entre as duas, elas não se confundem.

Estabilidade, conforme já definido, é a vantagem jurídica de caráter permanente deferida ao empregado em virtude de uma circunstância tipificada de caráter geral, de modo a assegurar a manutenção indefinida no tempo do vinculo empregatício, independentemente da vontade do empregador. Garantia de emprego, por sua vez, conforme já definido, é a vantagem jurídica de caráter transitório deferida ao empregado em virtude de uma circunstância contratual ou pessoal obreira de caráter especial, de modo a assegurar a manutenção do vinculo empregatício por um lapso temporal definido, independentemente da vontade do empregador. ${ }^{34}$

As hipóteses de garantia são, dentre outras:

a) Imunidade sindical: É vedada a dispensa do empregado sindicalizado a partir do registro da candidatura a cargo de direção ou representação sindical.

b) Dirigente da CIPA e Mulher Gestante: Estabilidade para o empregado de direção de comissões internas de prevenção de acidentes, desde o registro de sua candidatura até um ano após o final de seu mandado.

c) Acidente de trabalho: 0 trabalhador que sofrer acidente de trabalho terá garantia de emprego pelo lapso temporal de 12 (doze) meses.

34 DELGADo, Mauricio Godinho. Curso de Direito do Trabalho. São Paulo: Editora LTR75, 2011, p. 1184-1190. 
Vejamos os ensinamentos de Mauricio Godinho Delgado:

(...) há algumas garantias provisórias importantes.

Em primeiro lugar, a do empregado acidentado, que se estende pelo "prazo mínimo" de 12 meses, "após a cessação do auxílio-doença acidentário, independente de percepção de auxílio-doença (Art. 118, Lei no $8.213 / 01)^{35}$.

0 trabalhador que sofre acidente de trabalho e faz jus do auxílio-doença acidentário, quando recuperar sua aptidão para o labor, deverá se apresentar de volta na empresa para o trabalho. A partir do primeiro dia de retorno do trabalhador, este será possuidor de garantia de emprego pelos próximos doze meses. Vejamos:

0 art. 118 da Lei $\mathrm{n}$ - 8.213/91 garante a manutenção do contrato de trabalho na empresa ao segurado que sofreu acidente do trabalho pelo prazo mínimo de 12 meses, após a cessação do auxílio-doença acidentário, independentemente de percepção de auxílio-acidente ${ }^{36}$.

Como veremos na análise jurisprudencial, é muito comum no cotidiano, à empresa não realizar o preenchimento do CAT, de modo que o trabalhador se afaste recebendo o auxílio-doença, sendo assim, quando retorna ao seu posto de trabalho, não possui a estabilidade de 12 meses que lhe seria de direito, muitas vezes sendo despedido. No caso de auxílio-acidente também ocorre casos em que o trabalhador é liberado pelo INSS para retornar a suas atividades laborativas sem estar apto. Se o sinistro não tiver sido reconhecido como acidente de trabalho, o trabalhador no mesmo limbo jurídico que o beneficiário do auxílio-doença,

35 DELGADO, Mauricio Godinho. Curso de Direito do Trabalho. São Paulo: Editora LTR75, 2011, p. 1195.

36 VIANNA, João Ernesto Aragonés. Curso de Direito Previdenciário. São Paulo: Editora Atlas, 2013, p.630. 
enquanto recorre judicialmente fica sem receber salário nem benefício e muitas vezes é dispensado pela empresa.

\section{SITUAÇÃO DESUMANA DO TRABALHADOR, CONSEQUÊNCIAS E POSSÍVEIS MEDIDAS PARA AMENIZAR OS DANOS}

Conforme explica Maria Aparecida Gimenes ${ }^{37}$ em seu artigo cientifico, é comum chegar até o judiciário brasileiro, situações em que o trabalhador é posto em um limbo jurídico. Após ser acometido por uma enfermidade que exige o afastamento de suas atividades laborativas pelo prazo superior a 15 dias, o trabalhador recorre a Previdência Social, e passa a gozar do auxílio-doença comum ou acidentário. 0 trabalhador faz jus ao benefício até que ele volte a estar apto ao labor. Essa aptidão é atestada através de perícias médicas, realizadas de tempos em tempos pela autarquia. No entanto, a perícia médica considera o trabalhador apto ao retorno da empresa, lhe concedendo à alta, mas ao ser examinado pelo médico do trabalhado, esse considera que o empregado ainda permanece inapto às atividades laborativas, fazendo com que a empresa não autorize seu retorno ao trabalho. Ou seja, o empregado não recebe mais o benefício previdenciário, e não recebe salário da empresa.

Normalmente o caminho seguido pelo trabalhador, é recorrer da decisão administrativa do INSS, requerendo a reconsideração da perícia médica. Ao ter seu recurso negado, a única alternativa que lhe sobra é recorrer ao judiciário. Isso significa enfrentar toda a morosidade da Justiça sem ter nenhuma fonte de renda. Essa situação deixa o trabalhador em uma situação de vulnerabilidade, deixando de possuir o mínimo existencial, e consequentemente, ferindo gravemente o princípio da Dignidade da Pessoa Humana, conforme explica FERREIRA ${ }^{38}$.

37 GIMENES, Marcia Aparecida. Incapacidade Laboral e Benefício por AuxílioDoença do INSS. São Paulo: Editora LTr, 2014, p. 15.

38 FERREIRA, Dâmares. O princípio da dignidade da pessoa humana e os benefícios previdenciários. Revista de Direito do Trabalho, São Paulo v. 28. n. 105, 2002. 
Não é incomum, em um ato de desespero, para voltar prover seu sustento, que o trabalhador ajuíze uma ação na Justiça Federal, a fim de recorrer do indeferimento do auxílio-doença e outra ação na Justiça do Trabalho, contra o empregador por impedir sua volta. Essa situação pode ser de grande risco ao trabalhador, pois poderá obter duas decisões opostas, agravando sua situação.

\subsection{INDEFERIMENTO DO AUXÍLIO-DOENÇA}

Como sabemos, o INSS é uma autarquia federal, sendo assim, necessário se faz respeitar os princípios da administração pública, sendo um deles o da motivação. Ou seja, toda decisão administrativa deve ser motivada. 0 autor, Diogenes Gasparini (2006), explica esse princípio em sua obra, vejamos:

Os atos administrativos precisam ser motivados. Devem ser mencionadas para a prática de qualquer ato administrativos as razões de fato e de direito que levaram a Administração a proceder daquele modo. A motivação deve ser prévia e contemporânea à prática do ato ${ }^{39}$.

Portanto, ao indeferir um pedido de concessão ou prorrogação de auxílio-doença ou auxílio-acidentário, deve o perito deixar claro e de forma fundamentada os motivos de sua decisão. Infelizmente essa prática não vem sendo adotada no dia-a-dia, pois nos indeferimentos, não constam as razões médicas, pelas quais a autarquia está concedendo alta ao empregado.

É importante aclarar que ao analisar se um empregado faz jus ou não ao um benefício previdenciário, além das considerações técnicas da medicina, é de extrema importância levar em consideração a questão social. Ao invés de apenas olhar para a questão de saúde o perito deve analisar em qual

39 GASPARINI, Diogenes. Direito Administrativo. São Paulo: Editora Saraiva, 2006, p. 23. 
contexto social aquela pessoa está inserida. Analisar junto com a doença qual a atividade laborativa, qual a idade daquela pessoa, o ambiente em que ela vive e se sua condição socioeconômica vai possibilitar uma recuperação rápida, entre outros fatores. Eduardo Brol Sitta e Danusa Espindola de Morais, no artigo "Apontamentos críticos acerca dos benefícios por incapacidade do regime geral de previdência social na perspectiva dos direitos fundamentais sociais" escrevem sobre isso, vejamos:

(...) importante esclarecer, ainda, a existência da 'incapacidade social', formada pela jurisprudência pátria, no sentido de entender que o grau de incapacidade deve ser analisado de acordo com a situação socioeconômica e cultural do segurado, considerando o ambiente em que vive, sua idade, o tipo de limitação, sua capacitação profissional, além de seu grau de instrução ${ }^{40}$.

A questão do indeferimento do benefício previdenciário interfere diretamente na vida do trabalhador, podendo lhe causar sérios prejuízos, de modo que é inadmissível que a autarquia conceda a alta por motivos relapsos, sem a devida avaliação médica.

\subsection{ALTA PROGRAMADA}

Após a concessão do benefício previdenciário, a autarquia verifica se o trabalhador ainda faz jus ao benefício através das perícias médicas. No momento em que é concedido o benefício, o perito médico estima um tempo para a recuperação, que geralmente é de três meses. Portanto, 15 diasantes de findar esse prazo, se ainda não recuperado, o trabalhador deve agendar junto

$40 \quad$ MORAIS, Danusa Espindola de; SITTA, Eduardo Brol. Apontamentos críticos acerca dos benefícios por incapacidade do regime geral de previdência social na perspectiva dos direitos fundamentais e sociais. Revista Juris Plenum Trabalhista e Previdenciária: doutrina, jurisprudência, legislação. Caxias do Sul, v 06, n29, p.19-42, abr.2010. 
ao INSS o pedido de prorrogação do benefício, para que seja feita nova perícia. Contudo, muitas vezes o prazo de prorrogação é perdido pelo trabalhador, ou em muitas situações, ele não consegue agendar o pedido de prorrogação por não haver mais horários. Nessas situações, quando chega o término do prazo, o trabalhador para de receber o benefício, recebendo então uma alta programada, conforme explica Mauricio Matos Mendes ${ }^{41}$. Com o fim do benefício previdenciário o trabalhador está tecnicamente liberado para retornar ao labor, sem que seja feito nenhum tipo de exame médico.

No ano de 2017, no Rio Grande do Sul, a autarquia requereu que uma quantidade muito grande de beneficiários realizasse perícia médica, sob pena de terem seus benefícios cancelados. Ocorre que ao tentarem agendar horário, não conseguiam, pois havia uma grande quantidade de pessoas agendando esse atendimento. Consequentemente o INSS começou a cancelar os benefícios, mesmo não sendo culpa do trabalhador. Foi necessário que a Defensoria Pública da União ingressasse com uma ação coletiva para que os benefícios não fossem cancelados até a data da nova perícia, processo no 50021006920164047100 .

É importante ressaltar sobre as dificuldades das pessoas terem acesso ao INSS. Hoje em dia,conforme consta nas informações do site oficial da previdência social ${ }^{42}$, qualquer solicitação a ser feita, deve ser agendada através do telefone 135 e os resultados são disponíveis através do site da previdência social, o que dificulta o acesso a muitas pessoas que não possuem familiaridade com a tecnologia. O INSS, não possibilita outros meios para contemplar as pessoas que não sabem lidar com a tecnologia ou para as que não têm acesso. 0 sistema acaba sendo um dos maiores empecilhos para o trabalhador obter êxito em suas solicitações.

41 MENDES, Mauricio Matos. A alta programada e a previdência social. Revista Juris Plenum Trabalhista e Previdenciária, Caxias do Sul, v, 06, n.29, 2010.

42 https://www.inss.gov.br. 
Em sua obra, Eduardo Brol Sitta e Danusa Espindola de Moraisafirmam que a alta programada fere a segurança jurídica, vejamos:

\begin{abstract}
"Nessa quadra, cancelar o benefício de auxilio doença deferindo face ao reconhecimento de incapacitação para o trabalho por pericia médica do INSS e após considerar que o segurado estará apto para o trabalho em determinado prazo sem, contudo, qualquer avaliação médica regular propiciando ao segurado o adequado acesso a prova é procedimento que se revela atentatório ao principio da segurança jurídica que é essência do estado democrático de direito"43.
\end{abstract}

No mesmo sentido segue o autor Mauricio Mendes, em sua obra "A alta programada e a previdência social", como podemos ver no trecho abaixo, que a alta programada retira direitos consolidados do trabalhador, de maneira unilateral.

Na forma como atualmente se apresenta, a chamada "Alta Programada" fere direitos consolidados, uma vez que altera, sem previsão legal a natureza de instituto jurídico e invade direito alheio ao previamente fixar o prazo de cessação de incapacidade e operar a cessação do benefício de forma unilateral $^{44}$.

Percebe-se que a alta programada é mais uma falha do sistema previdenciário, no que diz respeito aos benefícios de auxílio-doença e auxílio-acidentário, que acarreta em muito prejuízo ao trabalhador, lhe deixando vulnerável.

43 MORAIS, Danusa Espindola de; SITTA, Eduardo Brol. Apontamentos críticos acerca dos benefícios por incapacidade do regime geral da previdência social na perspectiva dos direitos fundamentais e sociais. Revista Juris Plenum Trabalhista e Previdenciária, Caxias do Sul, v.06, n29, 2010.

44 MENDES, Mauricio Mattos. A alta programada e a previdência social. Revista Juris Plenum Trabalhista e Previdenciária: Caxias do Sul, 2010, p 65. 
A situação afirmada no trabalho, a qual o trabalhador se encontra após ter seu pedido de prorrogação do benefício previdenciário negado, sob o argumento de já estar apto ao labor e ser impedido de retornar ao trabalho, visto que é considerado inapto, fica clara na análise jurisprudencial apresentada a seguir.

\subsection{ANÁLISE JURISPRUDENCIAL}

Como vimos anteriormente, quando o trabalhador está acometido por alguma enfermidade, necessário se faz requerer o auxílio-doença ou o auxílio-doença acidentário ao INSS. No entanto, há casos em que finda o prazo estabelecido para recebimento do auxílio, mas o trabalhador ainda não está apto para o trabalho. Deste modo, solicita junto ao INSS o pedido de prorrogação do benefício e submete-se a nova perícia médica. Ocorre que, muitasvezes, o médico do INSS afirma que o trabalhador está apto a retornar a suas atividades laborativas, mesmo esse ainda não estando efetivamente capaz. Quando isso acontece, necessário se faz recorrer da decisão do INSS.

$\mathrm{Na}$ jurisprudência encontramos infinidades de casos concedendo judicialmente a reabilitação do benefício do auxílio doença, como verificamos no Agravo de Instrumento no 5032295 60.2017.4.04.0000/RS ${ }^{45}$ e na Apelação Cível no 5000213-

45 AGRAVO DE INSTRUMENTO. PREVIDENCIÁRIO. AUXÍLIO-DOENÇA. TUTELA DE URGENNCIA. PROBABILIDADE DO DIREITO.

1. Hipótese em que a tutela de urgência foi indeferida em primeiro grau de jurisdição, tendo o julgador singular entendido que "os atos administrativos contam com presunção de legitimidade e legalidade e, portanto, a revisão de um ato por parte do Judiciário depende da efetiva produção de prova capaz de demonstrar o erro da administração, o que, nesse momento, não se verifica no indeferimento por parte da autarquia".

2. Não obstante, há, nos autos, documentação recente dando conta de que o autor/agravante (encarregado operacional, técnico em química, 52 anos de idade) ainda padece de várias moléstias (esteve em gozo de auxílio-doença por 5 anos), estando atualmente com problemas na coluna e assolado por hepatite $C$, com fibrose avançada e indicação médica de ficar afastado de exposição a agentes químicos e produtos voláteis. Sendo assim, é de bom 
05.2011.4.04.7107/RS ${ }^{46}$. No entanto, não existe previsão legal para definir qual a situação do trabalhador perante a empresa enquanto este recorre judicialmente, visto que em tese deveria se apresentar para o labor, porém, na prática, ainda não possui capacidade laborativa. Em uma pesquisa jurisprudencial, é possível perceber que isso causa uma grande insegurança jurídica tanto para a empresa quanto para o trabalhador, pois cada um se comporta da maneira que entende ser coerente. Contudo, o maior prejudicado nessa situação é o trabalhador que além de estar enfrentando problemas de saúde, não recebe salário da empresa e nem benefício previdenciário. Podemos observar essa insegurança nos seguintes casos:

alvitre que seja restabelecido o benefício até, pelo menos, a realização de perícia na via judicial, quando então se terá um melhor panorama acerca do direito invocado.

3. Nesse contexto, preenchidos os requisitos para o deferimento da tutela de urgência, porquanto presentes nos autos manifestações médicas recentes a indicar a existência de incapacidade para a atividade habitual do autor/ agravante.

46 PREVIDENCIÁRIO. AUXÍLIO-DOENÇA. REQUISITOS. INCAPACIDADE. COMPROVAÇÃO. RESTABELECIMENTO. ART. 436 DO CPC.

1. Quatro são os requisitos para a concessão do benefício em tela: (a) a qualidade de segurado do requerente; (b) o cumprimento da carência de 12 contribuições mensais, (c) a superveniência de moléstia incapacitante para o desenvolvimento de qualquer atividade que garanta a subsistência, (d) o caráter temporário da incapacidade.

2. Comprovada a existência de impedimento para o trabalho, é de ser reconhecido o direito ao auxílio-doença, até que o segurado se encontre (re)abilitado ao exercício de atividade que lhe garanta a subsistência, ou, revelando-se tal providência inviável, seja o amparo convertido em aposentadoria por invalidez, nos termos dos artigos 59 e 62 da Lei 8.213/91.

3. Muito embora tenha o laudo pericial concluído haver aptidão para o trabalho, é certo que, uma vez demonstrada a incapacidade pelos demais elementos trazidos aos autos, é cabível, com base no art. 436 do CPC, a outorga do auxílio-doença, devendo esse ser restabelecido a partir do dia imediatamente posterior ao seu indevido cancelamento. 
Na ação no 0020853-40.2014.5.04.0022 ${ }^{47}$ do TRT4 a autora relatou que perdeu parcialmente a visão e teve seu pedido de prorrogação do benefício negado. Diante disso, mesmo não apta, voltou ao labor, pois precisava do salário para seu sustento, e ainda sim, logo após seu retorno foi dispensada. Porém, a Justiça Federal lhe concedeu o direito ao benefício de maneira retroativa, logo foi necessário ingressar com uma demanda na Justiça do Trabalho para poder ser reintegrada na empresa. Em contrapartida, na ação no 0021105-34.2014.5.04.0025 ${ }^{48}$ do TRT4, o autor, após ter seu pedido de prorrogação negado, recebeu uma carta da empresa para se apresentar ao labor em 48 horas. No entanto, como não possuía efetivamente a sua capacidade laborativa e estava recorrendo da decisão, o mesmo entendeu que não deveria se apresentar. Diante disso a empresa o despediu por justa causa. Posteriormente, houve decisão da Justiça Federal, lhe concedendo o benefício retroativamente, e a ação suprarreferida do TRT4 determinou a reintegração no emprego.

Além disso, em pesquisa na jurisprudência encontramos casos em que o trabalhador é colocado em um "limbo jurídico", como é o caso dos Recursos Ordinários nºs 0021739-29-

47 EMENTA

RECURSO ORDINÁRIO DO RECLAMANTE. NULIDADE DA DESPEDIDA. REINTEGRAÇÃO NO EMPREGO. É nula a despedida do empregado afastado do serviço em gozo de benefício previdenciário de auxílio-doença, ainda que a continuidade do período desse afastamento tenha sido declarada por ato judicial ou administrativo posterior ao efetivo desligamento. Cabível a reintegração no emprego, observando-se a suspensão do contrato de trabalho por força do benefício de auxílio-doença.

48 EMENTA

NULIDADE DE DESPEDIDA. Em caso de concessão de auxílio-doença pela Previdência Social, o empregado é considerado em licença não remunerada, durante o prazo desse benefício, na forma do disposto no art. 476 da CLT. 
2015.5.04.0402 ${ }^{49}$ e 0020073-50.2016.5.04.040450. Ambos tratam da seguinte situação: os trabalhadores requereram junto ao INSS a prorrogação do benefício do auxílio-doença e foram considerados aptos ao labor. Ao se apresentarem para o oficio, não foram aceitos de volta na empresa, pois o médico do trabalho afirmou que eles estavam inaptos.

Na Justiça do Trabalhoencontramos diversas ações reintegrando os trabalhadores às empresas, visto que foram dispensados no período da estabilidade, como é o caso do recurso ordinário no 0021374-66-2016-5.04.0231 ${ }^{51}$, em que o autor recebeu auxílio-doença ao invés do acidentário, devido ao fato da empresa não ter preenchido o CAT, logo após o retorno ao trabalho, foi demitido! 0 juiz da ação condenou, então, a empresa a indenizar

$49 \quad$ EMENTA

BENEFÍCIO PREVIDENCIÁRIO. CESSAÇÃO. SALÁRIOS DEVIDOS. Não se pode admitir que o empregado permaneça sem o recebimento dos salários e sem a percepção de auxílio-doença, sob pena de permanecer em um verdadeiro limbo jurídico e em situação de impossibilidade de prover o sustento próprio e o de sua família.

50 EMENTA

EMPREGADO CONSIDERADO APTO PELO INSS E INAPTO PELO EMPREGADOR. RESPONSABILIDADE DO EMPREGADOR PELO SALÁRIO NO PERÍODO DE INDEFINIÇÃO. Findo o benefício previdenciário do empregado, tendo este sido considerado apto pelo INSS para retorno ao trabalho e inapto pelo médico do empregador, tendo buscado diversas vezes o restabelecimento do benefício e lhe sendo negado o pedido, cabe ao empregador a responsabilidade pelos salários no período em que seu empregado encontrou-se em um limbo jurídico-previdenciário.

51 EMENTA ACIDENTE DO TRABALHO. EMISSÃO CAT. INDENIZAÇÃO DO PERÍODO ESTABILITÁRIO. A fruição de auxílio-doença comum, e não de auxílio-doença acidentário, decorre da inadequação do procedimento da demandada, ou seja, da não emissão oportuna da CAT. Não serve o tipo de benefício previdenciário auferido para obstar que se reconheça em juízo a caracterização do acidente de trabalho. Constatado o suporte fático para a incidência do artigo 118 da Lei $n^{\circ}$. 8.213/1991, impõe-se o reconhecimento da estabilidade provisória e a indenização correspondente ao período estabilitário, bem como diferenças de aviso prévio, férias com 1/3,13ํo salários e FGTS com 40\%. Provimento negado. 
o trabalhador. Já no processo no 0020593-20.2015.5.04.012152 a autora sofreu acidente do trabalho e mesmo debilitada permaneceu trabalhando, a doença se manifestou de uma maneira mais severa, já agravada, e então foi afastada requerendo o auxílio-doença, a própria perita do INSS reconheceu se tratar de acidente de trabalho. Quando retornou ao labor foi demitida. Posteriormente em decisão judicial foi reconhecido o acidente de trabalho e a estabilidade que dele decorre.

Em que pese à jurisprudência na maioria dos casos corrija as injustiças dos benefícios negados e das dispensas indevidas, os processos levam mais de ano para serem julgados e as pessoas ficam ao longo desse tempo sem ter seus direitos reconhecidos, na maior parte das vezes sem salário, o que causa grandes transtornos e prejuízos.

É evidente que precisamos encontrar uma solução para essa situação fática que coloca o trabalhador em estado de extrema vulnerabilidade. Na próxima seção apresentaremos algumas soluções.

\section{POSSÍVEIS SOLUÇÕES}

Como já vimos, o limbo jurídico em que o trabalhador é colocado quando o INSS o considera apto ao trabalho e o médico da empresa o considera inapto, causa grandes transtornos na vida do trabalhador, acarretando prejuízos irreparáveis.Emborao trabalhador esteja acometido de uma doença que o impede de laborar, não recebe nenhum tipo de renda, deixado o trabalhador e sua família em situação de vulnerabilidade, essa situação faz com que ele sofra um grande abalo emocional, e como se ainda não bastasse, restringe o acesso ao tratamento para que possa se

52 EMENTA ESTABILIDADE PROVISÓRIA. INDENIZAÇÃO. Tendo-se em vista a ocorrência de acidente típico, verifica-se que, na época da despedida, a reclamante era beneficiário de garantia no emprego, reputando-se nula a demissão ocorrida. 
recuperar. Essa situação agride violentamente o princípio da Dignidade da Pessoa Humana e o mínimo existencial, conforme versa Dâmares Ferreira em sua obra O princípio da Dignidade da Pessoa Humana e os benefícios previdenciários. Essa situação demonstra a urgência e a importância de se encontrar uma solução ${ }^{53}$.

Via de regra, quando o trabalhador ingressa com a ação judicial na Justiça Federal, recorrendo da decisão administrativa do INSS, requer a antecipação de tutela, que na maior parte das vezes é negada, conforme vimos na seção de análise jurisprudencial.

0 artigo 300 do Código de Processo Civil traz as hipóteses em que deve ser concedida a antecipação de tutela.

A tutela de urgência será concedida quando houver elementos que evidenciem a probabilidade do direito e o perigo de dano ou o risco ao resultado útil do processo ${ }^{54}$.

Pois bem, a probabilidade de direito fica clara quando o trabalhador junta ao processo o laudo de outro médico afirmando que não está apto ao trabalho acompanhado de exames médicos. Mais evidenciado ainda é o perigo de dano, posto que o trabalhador esta sem nenhuma fonte de renda, prejudicando sua sustentabilidadee de sua família.

Contudo, mesmo estando presentes os requisitos para a antecipação de tutela, na grande parte dos casos ela é indeferida, sob o argumento de que, se a ação for julgada improcedente o trabalhador não terá meios de devolver a autarquia previdenciária os valores recebidos indevidamente, causando um grande déficit na Previdência Social.

53 FERREIRA, Dâmares. O princípio da dignidade da pessoa humana e os benefícios previdenciários. Revista do Direito do Trabalho. São Paulo v 28. N 105, 2002.

54 BRASIL. Art. 300. Código Civil Brasileiro. 
Nos casos em que a ação é julgada procedente, o trabalhador recebe o valor dos benefícios previdenciários de maneira retroativa. Porém, não repara os danos já causados. Portanto, o meio utilizado atualmente pelo judiciário, encontra-se ineficaz, prejudicando o trabalhador.

É de extrema importância aclarar que a situação tratada no trabalho, ou seja, o limbo jurídico em que o trabalhador é colocado quando o INSS indefere o pedido de prorrogação do benefício alegando aptidão ao trabalho e o médico do trabalho não autoriza seu retorno, afirmando a inaptidão, pode ser evitado. Há uma maneira simples de prevenir essa situação, realizando perícias médicas de qualidade, com o suporte e amparo que o trabalhador necessita. Se as perícias médicas fossem mais bem realizadas, não haveria tantos laudos médicos contrários ao dos médicos do trabalho. Assim evitaríamos a situação desumana em que o trabalhador é colocado, não precisaria mover toda a máquina judiciária que já está superlotada, evitaríamos despesas para a união e também se evitaria dissabores dos empregadores, que por muitas vezes, também não sabem como agir perante o empregado nessas situações. Portanto, dentre as soluções propostas, não há dúvida que a mais eficaz é melhorar as perícias médicas da autarquia, para que tenham resultados mais precisos e verídicos. Ainda, cabe salientar, que é fundamental a ética profissional do médico perito que precisa produzir seu laudo médico da melhor maneira possível, respeitando todas as condutas médicas. Pois, além da responsabilidade médica, tem uma responsabilidade social. Essa solução, entretanto, demanda um aumento de despesas por parte da União, que deveria investir nas perícias do INSS.

O autor Marco Aurélio Marsiglia Treviso, escreve sobre outra possível solução: a competência da Justiça do Trabalho para as demandas de reestabelecimento de auxílio-doença, vejamos: 
ao trabalhador, a faculdade de, ao invés de propor ações distintas, ajuizar demanda única, contra o empregador e o INSS, cujo feito, por força da EC N 45/04, deverá ser processado e julgado pela Justiça do Trabalho, já que, no caso específico, a relação previdenciária é decorrente do contrato de emprego havido(2010 $)^{55}$.

De acordo com a proposta de Marco Aurélio, a ação deve ser julgada na Justiça do Trabalho, por ser uma Justiça mais célere e pelo fato do empregador poder fazer parte do polo passivo da relação jurídica. Deste modo, a antecipação de tutela poderia ser concedida, sem correr riscos do INSS não reaver os valores pagos indevidamente, caso julgada improcedente a ação. 0 processo seguirá o seguinte procedimento:

O trabalhador ajuizará a ação, recorrendo do indeferimento do benefício, na Justiça do Trabalho, cujos reclamados seriam o INSS e o empregador. A antecipação de tutela será concedida para garantir a fonte de renda do trabalhador. Se, ao decorrer do processo, ficar comprovado que o trabalhador realmente está apto ao labor, contrariando o laudo proferido pelo médico do trabalho, o juiz irá prolatar sentença nesses termos. Após, em fase de liquidação, o INSS apresentará extratos demonstrando os valores pagos indevidamente de benefício previdenciário, desde a concessão da antecipação de tutela até a decisão judicial. Contudo, quem deverá ressarcir o INSS será a empresa, posto que foi o médico do trabalho que proferiu laudo errôneo, criando empecilho ao trabalhador voltar para suas atividades laborativas. Deste modo, a antecipação de tutela poderá ser concedida, sem o grande risco do INSS não reaver os valores pagos indevidamente,

55 TREVISO, Marco Aurélio Marsiglia. A competência da justiça do trabalho para determinar o restabelecimento de benefícios previdenciários, como forma de garantir o acesso aos bens necessários para uma vida digna - análise da problemática do trabalhador que foi considerado apto ao trabalho pelo INSS e inapto pelo empregador. Revista LTr: São Paulo, 2010, p. 1091. 
pois, caso não haver o pagamento voluntário, poderá se iniciar a fase de execução.

Essa solução demonstra-se bastante razoável. Levando em consideração que a demanda será julgada em uma mesma ação, estando empregador e INSS no polo, torna-se acessívelo reembolso da autarquia, caso venha a ser indeferido o pedido de reestabelecimento de benefício. Além do mais, parece justo o desfecho, visto que o trabalhador não sai prejudicado, pois não foi ele que escolheu estar nesta situação. Portanto, o INSS arca com o valor dos benefícios até a sentença, se o trabalhador for considerado apto quem devolve o valor ao INSS é a empresa, já que foi essa que não possibilitou a volta do empregado.

Há outras duas hipóteses de solução. A primeira trata-se de uma solução de lege ferenda. Como já vimos anteriormente, existem, em nosso ordenamento jurídico, alguns casos de interrupção do contrato de trabalho. Nestes casos, o trabalhador não trabalha, porém recebe salário e esse lapso temporal em que o contrato está interrompido, conta como tempo de serviço. A solução é a seguinte, criar-se uma hipótese de interrupção do contrato de trabalho para o tempo em que o trabalhador estiver recorrendo, na via administrativa ou judicial, do indeferimento do benefício previdenciário. Assim, enquanto ocorre o processo, o trabalhador permanece recebendo o salário da empresa. Porém, se ao decorrer do processo, ficar comprovado que o trabalhador não está apto a retornar ao trabalho, contrariando a decisão do INSS, o empregador, apresentando os comprovantes de pagamento do salário, poderá ter o valor devolvido pela autarquia.A devolução dos valores poderia acontecer a partir de um requerimento junto ao INSS. Cabe salientar, que para a autarquia, em questão orçamentária, não haverá diferença, pois ao invés de pagar o valor do benefício retroativamente ao trabalhador, irá pagar para a empresa, que, no caso especifico, adiantou o pagamento ao trabalhador. Ou ainda, o repasse poderia ocorrer da mesma forma que 
atualmente acontece com o salário maternidade. 0 empregador faz o pagamento, e, posteriormente, o INSS faz o repasse através da dedução na Guia de Previdência Social (GPS).

A segunda hipótese trata de uma solução de lege lata. Como já vimos dentro das hipóteses de interrupção do contrato de trabalho, está previsto o afastamento do trabalhador por motivos de doença, nos 15 primeiros dias. Essa hipótese pode ser ampliada para contemplar também o lapso temporal em que o trabalhador se encontra no limbo jurídico tratado neste trabalho. A opção é plausível, visto que o trabalhador recebeu a alta do INSS, e, portanto, estaria apto ao retorno. Ocorre que se o médico do trabalho não indeferisse sua volta afirmando que este ainda não está capaz, o trabalhador por ainda estar doente, não teria condições de permanecer laborando e acabaria tendo que se afastar novamente do trabalho.

\section{CONCLUSÃO}

Como foi possível observar ao decorrer do trabalho, o tema tem uma grande importância social.Por isso precisa urgentemente ser tratado e revisto pelas autoridades competentes. É visível que o modus operandi utilizado atualmente é ineficaz, visto que causa prejuízos irreparáveis, para a parte mais vulnerável do processo e justamente aquela que deveria ser protegida.

Em outros tipos de ação já se demonstra bastante inaceitável as partes permanecerem aguardando por um longo tempo uma decisão judicial, tanto é assim que existe o principio da celeridade processual e a previsão legal de antecipação de tutela. Nas ações de indeferimento de benefício, esse tempo é ainda mais inadmissível, visto que trabalhador espera pela decisão sem ter fonte de renda, em muitos casos, necessitando desse dinheiro para poder alimentar a si e a sua família.

Em um Estado democrático de direito não pode ser aceito que pessoas permaneçam nesse grau de vulnerabilidade, tendo 
violado o principio da dignidade da pessoal humana e o mínimo existencial. É preciso rever o modo como a situação é tratada em nosso ordenamento jurídico.

Como vimos no presente trabalho uma das melhores maneiras para o problema ser resolvido é o da prevenção da situação, e isso pode facilmente ser solucionado se as perícias médicas obtiverem uma melhor qualidade e para isso será necessário maior investimento da União. Sabemos que a grande quantidade de demanda para pouco número de peritos prejudica a qualidade do trabalho, assim como a falta de estrutura. Mas, não podemos deixar de observar a responsabilidade do perito médico que não pode conceder a alta a um trabalhador sem ter a absoluta certeza que este se encontra capacitado. Uma decisão equivocada pode colocar o trabalhador nessa situação embaraçosa ou então fazer com que ele retorne ao labor e agrave ainda mais seu problema de saúde.

Não sendo possível evitar essa divergência entre a perícia médica do INSS e do médico do trabalho, cabe ao judiciário aplicar um método eficaz de solução para o conflito que não prejudique o trabalhador. Como explicado no trabalho, uma possível solução seria o da competência da justiça do trabalho, pois assim, o empregador poderá estar no polo passível da relação, a antecipação de tutela poderá ser concedida, e, se for o caso, a empresa será responsabilizada em devolver ao INSS, o valor pago indevidamente àtítulo de antecipação de tutela.

A solução da competência parece ser bastante razoável, pois responsabiliza o INSS quando indeferir o benefício de maneira errônea, mas também responsabiliza a empresa, quando o médico do trabalho profere laudo equivocado. E principalmente, deixa de ser o empregado que sofra com essa situação, pois ele é a pessoa que precisa de assistência e não o responsável pela a situação. Ainda podemos utilizar a legislação já existente e fazer uma interpretação ampliada das hipóteses de interrupção contratual, ou criar uma nova hipótese de interrupção do contrato prevendo 
exatamente que o contrato de trabalho fique interrompido enquanto o trabalhador recorre judicialmente da decisão do INSS. Não deixando, assim, o trabalhador no limbo jurídico.

Diante do exposto, fica evidente a necessidade de encontrar uma solução para essa situação, visto que embora seja uma situação corriqueira, está esquecida pelo legislador e pelos operadores do direito.

\section{REFERÊNCIAS}

ALMEIDA, André Luiz Paes de. Direito do Trabalho, São Paulo: Editora Rideel, 2014.

CASTRO, Carlos Alberto Pereira; LAZZARI, João Batista. Manual de Direito Previdenciário, Rio de Janeiro: Editora Forense, 2014.

DELGADO, Mauricio Godinho.Curso de Direito do Trabalho, São Paulo: Editora LTr, 2011.

DUARTE, Marina Vaques.Direito Previdenciário, São Paulo: Verbo Jurídico Ltda, 2012.

FARIAS, Thélio Queiroz. Acidente do Trabalho, Lemi: Anhanguera, 2011.

FERREIRA, Dâmares. 0 princípio da dignidade da pessoa humana e os benefícios previdenciários. Revista de Direito do Trabalho, São Paulo v. 28. n. 105, 2002.

FILHO, Evaristo de Moraes; MORAES, Antônio Carlos Flores. Introdução ao Direito do Trabalho, São Paulo: Editora LTr, 2010.

GASPARINI, Diogenes. Direito Administrativo, São Paulo: Editora Saraiva, 2006, p. 23

GIMENES, Marcia Aparecida, Incapacidade Laboral e Benefício por Auxílio Doença do INSS, São Paulo: Editora LTr, 2014.

GOUVEIA, Carlos Alberto Vieira de. Benefício por incapacidade e perícia médica: manual prático. 2. Ed., ver. e atual. Curitiba: Juruá, 2014.

JUNIOR, Miguel Horvath. Direito Previdenciário, São Paulo: Editora QuartierLatin, 2010.

LARA, Paulo Cesar de. "A incapacidade social" como fator a ser explorado positivamente nos laudos periciais para efeito da concessão de benefícios 
previdenciários ou assistenciais. Revista Brasileira de Direito Previdenciário. Porto Alegre, v.2, n. 10, 2012.

MARTINEZ, Wladimir Novares, Comentários á Lei Básica da Previdência Social, São Paulo: Editora LTr, 2010.

MENDES, Mauricio Matos. A alta programada e a previdência social. Revista Juris Plenum Trabalhista e Previdenciária, Caxias do Sul, v. 06, n 29, 2010.

MORAIS, Danusa Espindola de; SITTA, Eduardo Brol. Apontamentos críticos acerca dos benefícios por incapacidade do regime geral da previdência social na perspectiva dos direitos fundamentais sociais. Revista Juris Plenum Trabalhista e Previdenciária, Caxias do Sul, v. 06, n 29, 2010.

PASSOS, Fabio Luiz dos. A análise da incapacidade laborativa e o deferimento de benefícios previdenciários, São Paulo: LTr, 2015.

TREVISO, Marco Aurélio Marsiglia. A competência da justiça do trabaIho, a capacidade laborativa do trabalhador e o reestabelecimento de benefícios previdenciários, São Paulo: LTr, 2012.

TREVISO, Marco Aurélio Marsiglia. A competência da Justiça do Trabalho para determinar o reestabelecimento de benefícios previdenciários como forma de garantir o acesso a bens necessários para uma vida digna: análise da problemática do trabalhador que foi considerado apto ao trabalho pelo INSS e inapto pelo empregador, São Paulo: LTr, 2010.

TREVISO, Marco Aurélio Masiglia. $O$ acesso à Justiça do Trabalho: uma nova visão a respeito dos casos envolvendo a incapacidade laborativa do trabalhador e os benefícios previdenciários, Curitiba: Juruá, 2009.

VARGAS, Alberto de, Direito a reabilitação profissional, São Paulo: Editora LTr, 2017.

VIANNA, João Ernesto Aragonés, Curso de Direito Previdenciário, São Paulo: Editora Atlas, 2004. 